\title{
Microbial characterization of a natural biofilm associated with Peruvian scallop (Argopecten purpuratus) larvae settlement on artificial collector by confocal imaging, microbiology, and metagenomic analysis
}

\author{
José González-Pazmiño ${ }^{1,2}$, Krizia Maribell Pretell ${ }^{2}$, Karina Zapata-Vidaurre ${ }^{1}$ \\ Maribel Lucero Mesones ${ }^{3}$, Juan Quimí-Mujica² \& Benoit Diringer ${ }^{2}$ \\ ${ }^{1}$ Universidad Nacional de Tumbes, Tumbes, Perú \\ ${ }^{2}$ Inca'Biotec S.A.C., Tumbes, Perú \\ ${ }^{3}$ Servicios pesqueros DISMAR S.A.C., Sechura, Perú \\ Corresponding author: José González-Pazmiño (blgojosegonzalez@ gmail.com)
}

\begin{abstract}
Biofilms strongly influence bivalve settlement patterns on artificial substrates; however, their structure and taxonomic composition remains a black box. We characterized a natural biofilm composition that exhibits a large settlement of larvae of the Peruvian scallop Argopecten purpuratus by culture-dependent and culture-independent methods. Thirty-two different strains, representing six genera (10 strains of Bacillus, 9 of Vibrio, 6 Acinetobacter, 4 Staphylococcus, 2 Photobacterium, and 1 Exiguobacterium) were isolated. Those strains represented only $1.09 \%$ of the relative abundance compared with the total microbiota obtained by $16 \mathrm{~S}$ rRNA high-throughput sequencing. The metagenomic analysis identified 441 species. Prokaryotes were predominant (93.4\%) over eukaryotes (6.6\%), with Pelobacter (13.4\%), Lewinella (5.6\%), Marinobacter (5.4\%), Hoeflea (4.2\%), and Microcystis (3.1\%) being the most representative genera. Laser scanning confocal microscopy (LSCM) imaging evidenced an irregular and heterogeneous biofilm with an average thickness of 35 $\mu \mathrm{m}$, where the heterotrophic prokaryotic community $\left(3.4 \times 10^{6}\right.$ cell $\left.\mathrm{cm}^{-2}\right)$ dominate the photoautotrophic communities $\left(2.3 \times 10^{5}\right.$ cell $\left.\mathrm{cm}^{-2}\right)$. For the first time, an $A$. purpuratus settlement-related biofilm was described by the next generation sequencing tool (NGS) and compared with traditional methodologies.
\end{abstract}

Keywords: Argopecten purpuratus; biofilm; microbiota; settlement; larvae; NGS; LSCM

\section{INTRODUCTION}

The Peruvian scallop Argopecten purpuratus culture is one of the most economically valuable aquaculture sectors in Peru, with maximum production generating more than USD 160 million in 2013 (Bernendo-Quispe et al. 2016). However, after two decades of steady growth, the industry has faced several production decreases during the last six years. Drops in production yields are attributed to a) outbreaks related to harmful microalgae blooms and summer temperature rise, hypoxia, and b) the chronic shortage of A. purpuratus spat (Palomino-Ramos 2004, González-Hunt 2010, Murias 2015, Guerrero et al. 2016). A. purpuratus spat supply is mainly supported by manual extraction and collection on artificial substrates. Thus, Peruvian farms strongly depend on natural recruitment, which is highly fluctuating. The urgent need for spats has recently induced the emergence of many scallop hatcheries along the Peruvian coast.

For almost all bivalve species, the settlement and metamorphosis phase is the main bottleneck in scallop hatchery cultivation, and optimizing successful settlement is critical for the industry (Helm \& Bourne 2004, Gosling 2015).

The larvae's habitat preference strongly influences marine bivalves' recruitment patterns because they can choose to settle or not in response to positive or negative cues related to the substrate. These cues may indicate suitable food, adults, predators, or other environmental influences that signal a site's suitability to live. Previous research has shown that each bivalve species presents specific physical, chemical, and biological preferences to the substrate to settle and metamor-

Corresponding editor: Cesar Lodeiros 
phose into the juvenile form. Physical factors that can modulate settlement behaviors include color (Saucedo et al. 2005, Su et al. 2007), texture (Harvey et al. 1995, Taylor et al. 1998, Marsden \& Lansky 2000), surface (Yang et al. 2013), size of mesh (Wassnig \& Southgate 2012), and sounds (Eggleston et al. 2016).

In addition to the physical nature of the substrate, immersed surfaces are quickly colonized by microbial biofilm. Marine biofilm corresponds to the surfaceassociated communities of microorganisms such as bacteria and microalgae embedded within the extracellular polymeric substance (EPS) they secrete (Decho 2000, Shikuma \& Hadfield 2005). The development of a microbial biofilm on the substrate's surface may promote, inhibit, or have no effect on invertebrate settlement (Hadfield 2011).

The influence of different characteristic of natural microbial biofilms such as biofilm age, bacterial and microalgae composition and density, dry weight, chlorophyll and EPS content, and biochemical signals have been evaluated on bivalve settlement (Bao et al. 2007, Hadfield 2011, Toupoint et al. 2012, Wang et al. 2012, Campbell et al. 2015). It appears that microbial community structure more than microbial abundance has the most significant influence on biofilm efficiency at inducing bivalve settlement (Yu et al. 2008, Toupoint et al. 2012, Yang et al. 2013). Nevertheless, natural biofilm formation under uncontrolled conditions is highly variable due to natural environmental variations, in contrast to the standardized and effective technique for the synchronous induction of settlement of bivalve larvae under aquaculture.

From that perspective, some studies have evaluated the capacity of specific bacterial and microalgae strains isolated from the natural biofilm to induce bivalve settlement in oysters (Fitt et al. 1990, Tamburri et al. 1992, Anderson, 1996), pearl oysters (Zhao et al. 2003, Su et al. 2007, Yu et al. 2008), mussels (Satuito et al. 2005, Bao et al. 2007, Courtois de Viçose et al. 2010, Ganesan et al. 2010, Wang et al. 2012, Yang et al. 2013), clams (Van Colen et al. 2009), and scallops (Parsons et al. 1993, Leyton \& Riquelme 2008). Those works confirm that microbial stimulation of larval settlement and metamorphosis of the different bivalves is species-specific. Not necessarily correlated with bacterial density, there is a synergistic effect between waterborne and EPS/biofilms surface cues, and these cues remain to be adequately identified.

Altogether, those results give clues to understand the bivalve settlement process mediated by natural biofilms and fill the gaps to explain irregular settlement patterns in open waters and hatcheries. In this study, we propose for the first time to characterize the cultivable and non-cultivable microbial communities of a natural biofilm that coats an artificial substrate that is massively colonized by recently settled A. purpuratus larvae from Sechura Bay (Peru). The entire bacterial community will be revealed using the next generation sequencing tool (NGS) to determine the metagenome that comprises the biofilm based on 16S rRNA sequences. Cell density and biofilm composition will also be explored through imaging by laser scanning confocal microscopy (LSCM). Finally, we will compare the cultivable and uncultivable microbial communities to estimate their representativeness. This study is, to our knowledge, the first to characterize by metagenomic the microbial composition of an "attractive" biofilm for bivalve settlement.

\section{MATERIALS AND METHODS}

\section{Biological samples}

Biofilm samples were collected in Sechura Bay $\left(5^{\circ} 74 ' 30.35^{\prime}\right.$ 'S, $\left.81^{\circ} 01^{\prime} 24.47^{\prime \prime} \mathrm{W}\right)$ from a 30 days old "Netlon" ${ }^{\circledR}$ collector with a $1 \mathrm{~cm}$ opening mesh, installed for commercial spat collection operations by visual selection. Netlon pieces that exhibit great patches of settlement $\left(>20\right.$ spat $\left.\mathrm{cm}^{-2}\right)$ were cut and transported directly to the laboratory in wide-mouth bottles filled with Netlon submerged in water inside cool boxes at $12-15^{\circ} \mathrm{C}$. Samples were quickly processed for bacterial analysis and LSCM analysis in December 2016.

\section{LSCM imaging of surface biofilm}

Netlon pieces of $1 \mathrm{~cm}^{2}$ were stained with $1 \%$ ethidium bromide (ETB) for $10 \mathrm{~min}$ in the absence of light. Confocal imaging was performed with a FluoView FV10i (Olympus) confocal laser scanning microscope according to established protocols by Lee et al. (2004). ETB fluorescence was visualized with excitation/ emission wavelengths of $650-800 \mathrm{~nm}$, chlorophyll autofluorescence was detected at 460-650 nm. Images acquisition was realized under identical conditions. Biofilm thickness was evaluated by visualizing the appearance and disappearance of fluorescence, realizing slices in the $\mathrm{Z}$ dimension. The cell density was analyzed using Image $2^{\circledR}$; the bacterial, microalgae, and cyanobacteria counts were performed using an RGB range 0-7, 66-87, and 41-42, respectively, following the specifications of Bankhead (2014). Filamentous cyanobacteria chains were considered as one cell.

\section{Culture and phylogenetic analysis of bacteria}

A piece of $10 \mathrm{~cm}^{2}$ Netlon was washed with autoclaved filtered seawater (AFSW) to remove unattached bacteria. The Netlon piece was scraped with a dispo- 
sable wooden stick in AFSW. Serial dilutions of the solution were plated in triplicate on Marine agar (Difco, MA2216), Triptona Soy agar supplemented with 2\% $\mathrm{NaCl}$, and yeast extract at $1 \%$ at room temperature. All phenotypically distinguishable colonies, based on their morphology (e.g. texture, shape, and color), were selected to isolate as many different strains as possible. About 2-4 per plates were randomly selected. The purification process was done by the streaking method, and Gram coloration assessed purity. This process was repeated until pure colonies were obtained. Pure strains were cultivated in $\mathrm{LB}$ supplemented with $2 \% \mathrm{NaCl}$. For long-term storage, sterile glycerol was added to $1 \mathrm{~mL}$ bacterial culture $(15 \% \mathrm{v} / \mathrm{v})$ and stored at $-20^{\circ} \mathrm{C}$. At molecular characterization, $1 \mathrm{~mL}$ cultures of the isolated strains were lysed, and DNA was extracted by the CTAB method described by William \& Feil (2012). The 16S rRNA gene was partially amplified using the universal primers 27F (5'- AGAGTTTAGTCMTGG CTCAG-3) - 1492R (GGYTACCTTGTTACGACTT) in $25 \mu \mathrm{L}$. PCR reactions that contained $\sim 50 \mathrm{ng}$ genomic DNA, 0.5 units Platinum Taq DNA polymerase (Thermo Scientific), $1 \mathrm{X}$ Taq buffer, $2 \mathrm{mM} \mathrm{MgCl}_{2}, 15$ pmol of each primer, and $0.2 \mathrm{mM}$ dNTP mix, yielding $\sim 1500$ bp PCR products. PCR parameters were initially denatured for $5 \mathrm{~min}$ at $95^{\circ} \mathrm{C}$ followed by 35 cycles of denaturation at $95^{\circ} \mathrm{C}$ for $30 \mathrm{~s}$, hybridization at $55^{\circ} \mathrm{C}$ for $45 \mathrm{~s}$, elongation at $72^{\circ} \mathrm{C}$ for $1 \mathrm{~min}$, and final elongation at $72^{\circ} \mathrm{C}$ for $10 \mathrm{~min}$. PCR products were controlled using $1.5 \%$ agarose gel electrophoresis before sequencing by the Sanger method (Macrogen Inc., USA) using internal primers 518F (CCAGCAGCCGCGGTAAT ACG)-800R (TACCAGGGTATCTAATCC). Only high-quality sequences of the partial $16 \mathrm{~S}$ rDNA were used. They were checked with Bioedit before being compared with a curated database Ezbiocloud (Yoon et al. 2017) to identify bacteria strains at genus (97-98\% identity) or species (99-100\% identity) level. Strains with a level of identity inferior to $97 \%$ were not selected.

\section{S rRNA amplicon sequencing and analysis}

For the NGS analyses, a piece of $10 \mathrm{~cm}^{2}$ Netlon was washed with AFSW. Before being collected by centrifugation at $4000 \mathrm{rpm}$ for $30 \mathrm{~min}$, the biofilm was detached by vortex and ultrasonication $(5 \mathrm{~min}$ at 40 $\mathrm{kHz}$ ) to recover the biofilm pellet. Extraction was performed with the MOBIO Power Soil DNA Isolation Kit (MOBIO Laboratories Inc., Carlsbad, CA, USA) following the manufacturer's instructions. The 16S rRNA gene V4 variable region was used as the target sequence. It was amplified using PCR primers $515 \mathrm{~F}$ and 806R that were used in a single-step 30-cycle PCR, using the HotStar Taq Plus Master Mix Kit (Qiagen, USA) under the following conditions: $94^{\circ} \mathrm{C}$ for $3 \mathrm{~min}$ followed by 28 cycles ( 5 cycles used on PCR products) of $94^{\circ} \mathrm{C}$ for $30 \mathrm{~s}, 53^{\circ} \mathrm{C}$ for $40 \mathrm{~s}$, and $72^{\circ} \mathrm{C}$ for $1 \mathrm{~min}$, after which a final elongation step at $72^{\circ} \mathrm{C}$ for $5 \mathrm{~min}$ was performed. Sequencing was performed at MR DNA (www.mrdnalab.com, Shallowater, TX, USA) on an Ion Torrent PGM following the manufacturer's guidelines. Sequence data were processed using a proprietary analysis pipeline (MR DNA, Shallowater, TX, USA). In summary, sequences were depleted of barcodes and primers, sequences $<150$ bp were removed, and sequences with ambiguous base calls and homopolymer run exceeding $6 \mathrm{bp}$ were removed. Sequences were denoised, operational taxonomic unit (OTUs) generated, and chimeras removed. Clustering defined OTUs at a $3 \%$ divergence ( $97 \%$ similarity) level. Final OTUs were taxonomically classified using BLASTn against a curated database derived from RDPII.

For comparing $16 \mathrm{~S}$ rRNA data between cultured isolated and metagenomic sequences, the Fasta file was run in RDP Naive Bayesian rRNA Classifier Version 2.11, September 2015 (http://rdp.cme.msu.edu) to compare the shared taxa at the genus level.

\section{RESULTS}

\section{Confocal imaging by LSCM}

Analysis of datasets recorded by LSCM revealed that biofilm had an average thickness of $35 \pm 14 \mu \mathrm{m}$ and presented a dense and diverse population of bacteria, cyanobacteria, and microalgae (Fig. 1). The bacteria size ranged from 1 to $3 \mu \mathrm{m}$, and bacilli and cocci populations were generally mixed and distributed all over the substrate. The observed microalgae mainly belong to diatoms with size ranging from 5 to $40 \mu \mathrm{m}$.

The mean concentration of bacteria was $3.4 \times 10^{6}$ cell $\mathrm{cm}^{-2}\left( \pm 1.2 \times 10^{6}\right.$ cell $\left.\mathrm{cm}^{-2}\right)$, and the mean eukaryote photosynthetic cell concentration was $2.1 \times 10^{5} \mathrm{cell} \mathrm{cm}^{-2}$ $\left( \pm 8.4 \times 10^{4}\right.$ cell $\left.\mathrm{cm}^{-2}\right)$ in a relation of $16: 1(34.4 / 2.2)$ bacteria/microalgae, respectively (Table 1 ). Cyanobacteria were counted at $1.3 \times 10^{4}$ cell cm$~_{-2}\left( \pm 7.1 \times 10^{3}\right.$ cell $\mathrm{cm}^{-2}$ ) and were identified by orange color due to the combination of chlorophyll- $\alpha$ autofluorescence (green) and nucleic acid staining (red). The total microalgae count represents $6.35 \%$ of the total prokaryote count, while cyanobacteria represent $0.4 \%$.

\section{Culture-dependent composition of bacteria from settlement biofilm}

Thirty-two bacterial colonies were isolated and successfully identified according to their 16S rRNA sequences (Table 2). All sequences presented high levels of similarity (>99.7\%) and could be classified in 28 different strains according to their closest Ezbiocloud 

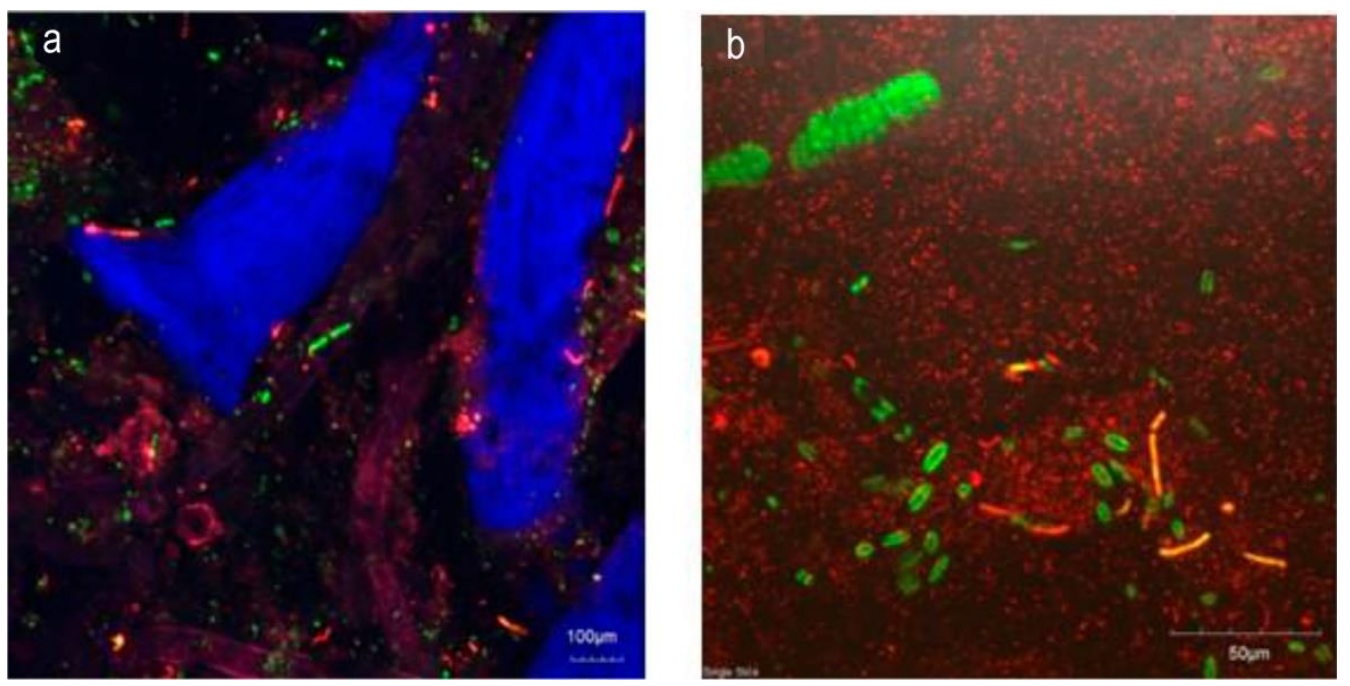

Figure 1. Laser scanning confocal microscopy (LSCM) datasets are showing biofilms developed on Netlon collectors associated with Argopecten purpuratus settlement at a) 10x and b) 60x. Color allocations: blue: Netlon reflection; green: autofluorescence of chlorophyll- $\alpha$; red: nucleic acid staining with ETB; orange: nucleic acid staining + autofluorescence of chlorophyll- $\alpha$.

Table 1. Cell counts of microorganisms constitute a natural biofilm collected from commercial collectors with Argopecten purpuratus settlement obtained by laser scanning confocal microscopy (LSCM) images analysis. *Data excluded due to great structures of Netlon that modify the Z cut, SD: standard deviation.

\begin{tabular}{lcccccc}
\hline Item & Bacteria cm $^{-2}$ & Microalgae $\mathrm{cm}^{-2}$ & Cyanobacteria $\mathrm{cm}^{-2}$ & $\begin{array}{c}\mathrm{Z} \\
(\mathrm{cut})\end{array}$ & $\begin{array}{c}\text { Size } \\
\left(\mu \mathrm{m} \mathrm{cut}{ }^{-1}\right)\end{array}$ & $\begin{array}{c}\text { Thickness } \\
(\mu \mathrm{m})\end{array}$ \\
\hline Photo1 & $4.54 \mathrm{E}+06$ & $3.17 \mathrm{E}+05$ & $1.75 \mathrm{E}+04$ & 12 & 4 & 48 \\
Photo2 & $2.56 \mathrm{E}+06$ & $1.31 \mathrm{E}+05$ & $2.19 \mathrm{E}+03$ & 15 & 1 & 15 \\
Photo3 & $4.37 \mathrm{E}+06$ & $1.59 \mathrm{E}+05$ & $8.74 \mathrm{E}+03$ & 14 & 2 & 28 \\
Photo4 & $1.43 \mathrm{E}+06$ & $1.38 \mathrm{E}+05$ & $1.75 \mathrm{E}+04$ & 24 & 2 & 48 \\
Photo5 & $3.55 \mathrm{E}+06$ & $2.67 \mathrm{E}+05$ & $2.21 \mathrm{E}+04$ & 32 & 4 & $128^{*}$ \\
Photo6 & $4.17 \mathrm{E}+06$ & $2.96 \mathrm{E}+05$ & $1.51 \mathrm{E}+04$ & 24 & 1,5 & 36 \\
\hline Average & $3.44 \mathrm{E}+06$ & $2.18 \mathrm{E}+05$ & $1.38 \mathrm{E}+04$ & & & 35 \\
SD & $1.22 \mathrm{E}+06$ & $8.44 \mathrm{E}+04$ & $7.18 \mathrm{E}+03$ & & & 14.03 \\
\hline
\end{tabular}

equivalent. These strains were clustered in two main clades (Firmicutes and Proteobacteria). They were representing, respectively, four families (Bacillaceae, Vibrionaceae, Staphylococcaceae, and Moraxellaceae) for a total of six genera (Bacillus and Vibrio (nine strains each), Staphylococcus and Acinetobacter (four strains each), and Photobacterium and Exiguobacterium (one strain each). Altogether, the isolates belonged to 18 different species, with Acinetobacter soli being the most prevalent (15.6\%), followed by Bacillus nealsonii, B. haynesii, and Vibrio nereis (9.4\% each). Nine species were recovered only once. The sequences were uploaded in the Genbank-NCBI repository: "MK874912-MK874941."

\section{Culture-independent composition of bacteria from settlement biofilm}

Analysis of DNA sequences by PGM produced 88,852 raw reads, with a coverage size of $265 \mathrm{bp}$. After removal of $19.6 \%$ of obtained sequences, a total of 71,410 valid readings were used to estimate the bacterial richness. A total of 1113 operational taxonomic units (OTUs) based on a $>97 \%$ identity cutoff for bacterial $16 \mathrm{~S}$ rRNA genes were obtained. Those OTUs belonged mainly to prokaryotes $(93.4 \%)$ and, to a lesser extent, eukaryotes (6.6\%). The data are registered as MG-RAST ID: mgm4796679.3 and NCBI Biosample: SAMN14531558 
Table 2. Culture-dependent microbiota isolated from biofilms developed on Netlon collectors associated with Argopecten purpuratus settlement.

\begin{tabular}{|c|c|c|c|c|c|}
\hline $\begin{array}{l}\text { Number of } \\
\text { repeated isolates }\end{array}$ & Strain code & Top hit taxon & $\begin{array}{c}\text { Similarity } \\
(\%)\end{array}$ & $\begin{array}{l}\text { Seq length } \\
\text { (bp) }\end{array}$ & Accession \\
\hline 2 out of 19 & 4BCA/6BCA & Bacillus licheniformis & 99.67 & 918 & AE017333 \\
\hline \multirow[t]{3}{*}{2 out of 19} & 32BCA/29BCA & Vibrio rotiferianus & 99.89 & 919 & AJ316187 \\
\hline & 35BCA & Staphylococcus epidermidis & 99.78 & 922 & RPSA01000015 \\
\hline & 38BCA & Vibrio fortis & 100 & 723 & AJ514916 \\
\hline 3 out of 19 & $9 \mathrm{BCA}$ & Vibrio owensii & 100 & 1384 & JPRD01000038 \\
\hline \multirow[t]{2}{*}{2 out of 19} & 10BCA/11BCA & Photobacterium damselae subsp. piscicida & 99.93 & 1500 & X78105 \\
\hline & $13 \mathrm{BCA}$ & Bacillus & 91.82 & 1042 & AE016877 \\
\hline \multirow[t]{2}{*}{3 out of 19} & 15BCA/20BCA/40BCA & Bacillus paralicheniformis & 99.71 & 1358 & KY694465 \\
\hline & $18 \mathrm{BCA}$ & Bacillus paramycoides & 99.85 & 1347 & MAOI01000012 \\
\hline 2 out of 19 & $28 \mathrm{BCA}$ & Bacillus paranthracis & 99.86 & 1489 & MACE01000012 \\
\hline 3 out of 19 & $34 \mathrm{M} / 36 \mathrm{M} / 37 \mathrm{M}$ & Acinetobacter seifertii & 99.31 & 1466 & KB851199 \\
\hline
\end{tabular}

Within the prokaryotes cluster, the number of OTUs detected in the biofilm sample was 1039, representing 306 genera distributed in 125 families, 71 orders, 32 classes, and 14 phyla (Fig. 2). The most abundant phylum was Proteobacteria (77.5\%), followed by Bacteroidetes (11.2\%) and Planctomycetes (5.3\%). In the Proteobacteria phylum, the $\alpha$-protobacteria class was predominant with $38.2 \%$, followed by $\gamma$ proteobacteria $20.03 \%$ and $\delta$-proteobacteria $18.16 \%$. In the $\alpha$-protobacteria, the most representative orders were Rhodobacterales (26.9\%), Rhizobiales (8.1\%), and Sphingobacteriales (7\%). In the $\gamma$-proteobacteria, the most representative orders were Alteromonadales $(8.4 \%)$, Pseudomonadales (5\%), Oceanospirillales (2\%), and Enterobacteriales (1.5\%). Concerning the $\delta$ proteobacteria class, Desulfuromonadales $(14.3 \%)$ and Myxococcales $(2.3 \%)$ were the most representative orders. At the genus level, Pelobacter ( $\delta$-proteobacteria) was the most abundant genus with $13.4 \%$ followed by Lewinella (Sphingogobacteria) 5.6\%, Marinobacter ( $\gamma$-proteobacteria) 5.4\%, Hoeflea $(\alpha-$ protobacteria) $4.7 \%$, Pseudomonas ( $\gamma$-proteobacteria) 4.2\%, and Microcystis (cyanobacteria) 3.1\%.

Within the eukaryote cluster, 69 OTUs were reported and comprised only nine genera representing $2.1 \%$ of the total genus richness. They mainly belong to diatoms, with Bacillaria being the predominant genus $(32.9 \%)$ followed by Emiliania $(29.0 \%)$ and Ditylum, Haslea, and Thalassiosira (11.0, 10.9, and $10.4 \%$, respectively) and, to a lesser extent,
Skeletonema, Phaeodactylum, and Nitzschia (>3\%). The eukaryotic OTUs represent $6.6 \%$ of the prokaryotic metagenomic OTUs.

\section{Comparison of the cultivable strains and metage- nomic sequences with PGM library}

The 16S rRNA sequences from the metagenomic library were compared with the sequences obtained from isolated strains at the genus level (Table 3). Of the six genera identified by culture-dependent method isolated, five matched with one of the 306 genera identified by PGM, representing $1.63 \%$ of the metagenome's library's genus richness and $1.086 \%$ of the valid readings (relative abundance). The most shared genera and representative in the whole metagenome sequences were Vibrio $(0.547 \%)$, Acinetobacter (0.499\%), and Staphylococcus (0.024\%).

\section{DISCUSSION}

The improvement of natural recruitment of Argopecten purpuratus has been the subject of intensive studies to ensure the catering of seeds for the aquaculture industry in Peru and Chile. These studies include the evaluation of different substrates, the water depth for the installation of collectors, the use of shell litter on the bottom as well, as the use of cultivable microbial strains to increase the larval settlement in hatcheries and the open sea (Pacheco \& Stotz 2006, Leyton \& Riquelme 


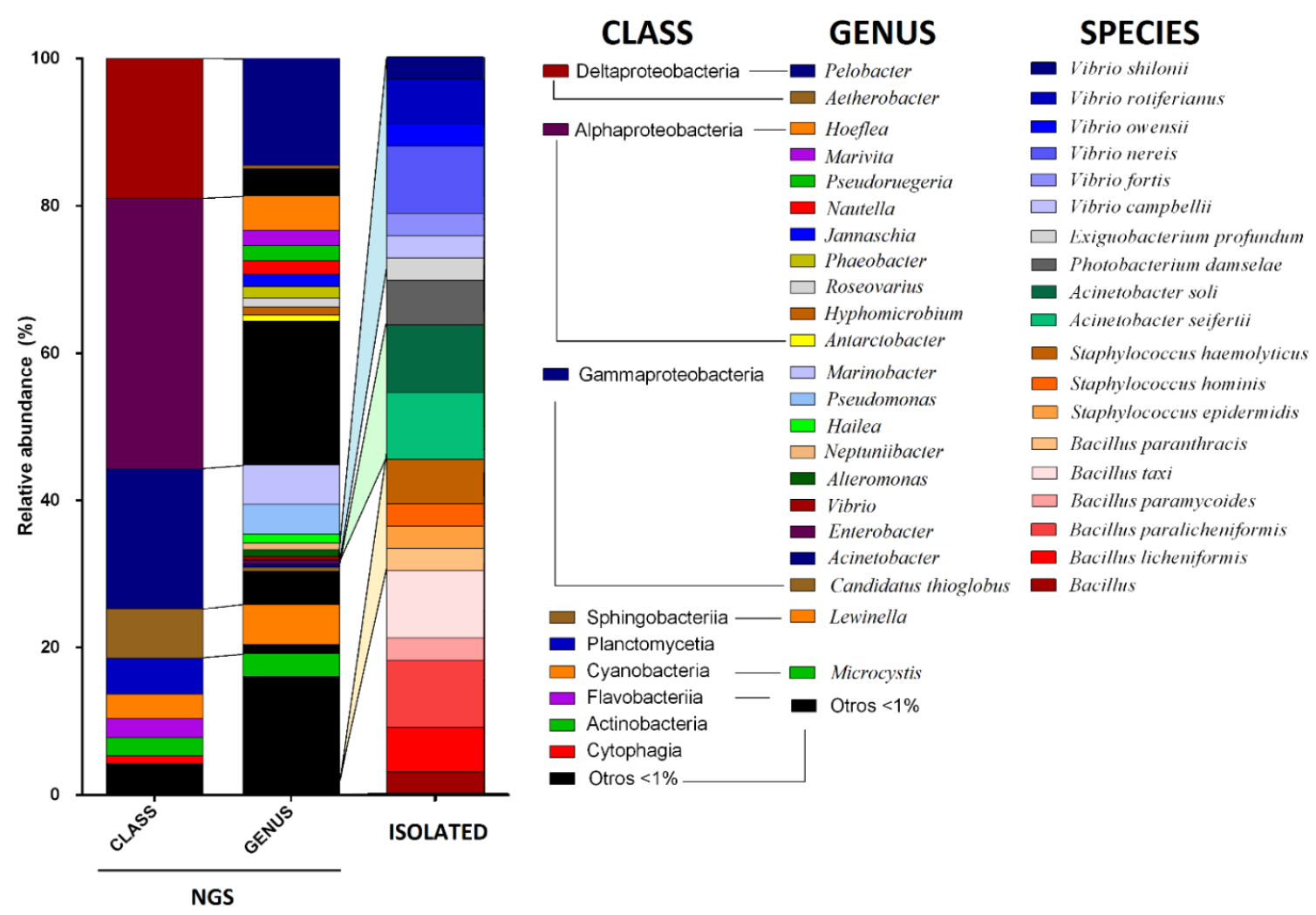

Figure 2. Relative abundance comparison of the biofilm microbiota was collected from a Netlon collector associated with Argopecten purpuratus settlement obtained by metagenomic and culture-dependent methods. The first and second columns represent classes and genus compositions obtained by next generation sequencing (NGS) metagenomics. The third column represents the species composition of isolated bacteria.

2008, Cantillanez et al. 2010). In this study, we described for the first time the microbiota community that comprises a spontaneous biofilm stimulates large settlements of A. purpuratus larvae.

\section{Comparison of LSCM and PGM analyses}

The bacteria-to-microalgae ratio estimation, obtained from LSCM count imaging and PGM OTUs analysis, were approximately $16: 1$ and $15: 1$, respectively. Which is close to the spontaneous biofilms used in pearl oyster settlement-inducing experiments (Yu et al. 2008), but far less than the ratios of 160:1 to 1000:1 reported from marine biofilm observed worldwide (Khandeparker et al. 2002, Railkin 2003). The significance of bacteria/ microalgae ratio on $A$. purpuratus settlement is unknown. It should be studied to understand if the ratio balance, the microbial density, the microbial identity, or a combination of those affects bivalve settlement.

LSCM and PGM analyses' main difference lies in microalgae identification because observed species differ significantly from those obtained by molecular taxonomy. This difference is due to the lack of a universal molecular marker for microalgae or diatom taxonomy, particularly for NGS (Steven et al. 2012, Toupoint et al. 2012, Kermarrec et al. 2013, Zimmermann et al. 2015). To date, eukaryotic autotrophic communities are still mainly identified using microscopy. The 16S rRNA is convenient for ecological interaction monitoring. It identifies both bacteria and microalgae and has an increasing number of available sequences (Decelle et al. 2015) even if, for the moment, its use is somewhat more quantitative than qualitative.

Some studies refer that biofilm thickness and biofilm age directly modulates some bivalve species fixation (Toupoint et al. 2012) and others that refuse fixation (Yang et al. 2013). In our study, biofilm covered most of the Netlon, with few non-colonized spaces. Some biofilm thickness fluctuations could be observed; however, these were kept within the average range observed elsewhere for either spontaneous or monospecific marine biofilms (Mueller et al. 2006, Hadfield 2011, Toupoint et al. 2012, Natrah et al. 2014, Mitra et al. 2015). A. purpuratus settlement behavior may not be related to the absolute abundance or the biofilm's thickness, but rather its specific composition. 
Table 3. Comparison of relative abundance between cultured isolated bacteria and metagenomic sequences at the genus level. NGS: next generation sequencing tool.

\begin{tabular}{lccccc}
\hline \multirow{2}{*}{ Genus } & \multicolumn{2}{c}{ Culture-dependent } & & \multicolumn{2}{c}{ Metagenomic } \\
\cline { 2 - 3 } \cline { 5 - 6 } & $\begin{array}{c}\text { \# of } \\
\text { isolated }\end{array}$ & $\begin{array}{c}\text { Relative } \\
(\%)\end{array}$ & & $\begin{array}{c}\text { \# of NGS } \\
\text { Sequence data }\end{array}$ & $\begin{array}{c}\text { Relative } \\
(\%)\end{array}$ \\
\hline Bacillus & 10 & 31.3 & & 01 & 0.012 \\
Vibrio & 09 & 28.1 & & 03 & 0.547 \\
Acinetobacter & 06 & 18.8 & & 04 & 0.499 \\
Staphylococcus & 04 & 12.5 & & 02 & 0.024 \\
Photobacterium & 02 & 6.3 & & 01 & 0.004 \\
Exiguobacterium & 01 & 3.1 & & 0 & 0.000 \\
\hline Total & 32 & 100.0 & 11 & 1.086 \\
\hline
\end{tabular}

\section{Comparison between culture-dependent and culture-independent microbiology}

PGM has been previously used for analyzing the marine community (Fujimoto et al. 2014, Brinkmeyer 2016) and was successfully used to characterize the relative abundance of microbial genera present in the biofilm. According to PGM analysis, the biofilm's most abundant phyla were Proteobacteria and Bacteroidetes, in relative proportions to the samples processed by Dang et al. (2008) from the Yellow Sea. Isolated strains belonged only to Firmicutes and $\gamma$-proteobacteria, and represented six bacterial genera. Previous studies report that the phylum $\gamma$-proteobacteria strongly predominate the culture-dependent microbiota of marine biofilms associated with the settlement of larvae of bivalve, sea urchin, Polychaeta, and algae zoospores. In contrast, the genera Pseudoalteromonas, Vibrio, Alteromonas, and Shewanella are the most frequently isolated bacteria (Lau et al. 2002, Patel et al. 2003, Huggett et al. 2006, Yang et al. 2013, Dobretsov \& Rittschof 2020, Vijayan \& Hadfield 2020).

In this study, the absence of Pseudoalteromonas and the substantial prevalence of Bacillus and Staphylococcus are remarkable. Some Bacillus and Staphylococcus strains have been shown to promote mussel and Polychaeta larval settlement (Lau et al. 2002, Ganesan et al. 2010, Freckelton et al. 2017) and were found in high prevalence on recently settled abalone and its substrate (Jiang et al. 2017). As specific strains from the same genus may present a settlementinducing, non-inducing, or even antifouling activity, further studies are necessary to determine the relevance of Firmicutes' presence on A. purpuratus larvae settlement.

On the contrary, the absence of isolated Pseudoalteromonas, a common cultivable and invertebrate settlement-inducing bacterium (Peng et al. 2020), is probably due to its actual non-existence as this genus grows well on the culture mediums used in this study and because its DNA represented only $0.04 \%$ of the valid reads obtained by PGM.

The NGS data pointed out that the isolated bacteria did not belong to any dominant order and represented only a little more than $1 \%$ of the whole biofilmassociated microbiota, thus confirming that the bacterial community's culture-dependent methods analysis are obsolete (Amann et al. 1995). Peng et al. (2020) also described a very low correlation between the more prevalent genus identified by NGS and the most isolated genus from a biofilm inducing the settlement of the polychaete Hydroides elegans.

Sequences of the genus Pelobacter and Lewinella were the most frequent ones obtained by NGS in our study. Those bacteria frequently inhabit marine sediment and other aquatic reducing environments (Schink 2006). The Sechura Bay is located at the northern extension of the Peruvian upwelling system. Its high productivity is associated with the oceanic's intermittent rises to the surface (Tarazona \& Arntz 2001). The suspension of these anoxic particles and nutrients could explain the abundance of soil and the biofilm's reducing environment.

Other bacterial genera dominant in the biofilm (such as Hoeflea, Marinobacter, and Pseudomonas) have been described to exhibit algaecidal or stimulatory effects toward microalgae (Palacios et al. 2006, Keawtawee et al. 2012, Ritchie 2012, Natrah et al. 2014, Ramanan et al. 2016). Moreover, to directly or through their exudate, either inhibit or favor invertebrate settlement (Khandeparker et al. 2002, Huggett et al. 2006, Salta et al. 2013, Sharp et al. 2015). Moreover, Hoeflea is dominant within the microbiota associated with abalone larvae and their settlement substrate based on NGS analysis (Jiang et al. 2017). In contrast, some cultivable Pseudomonas and Marinobacter species are abundantly founded in $A$. purpuratus larval rearing (Godoy et al. 2011). 
Altogether, these results suggest that our mixotrophic biofilm was principally composed of microorganisms that were biofilm specialists concerning microalgae or the settlement of invertebrate larvae or marine sediment. This pattern is correlated with the high primary productivity and high nutrient environment of the Sechura Bay.

Successful settlement and metamorphosis rates of A. purpuratus larvae rarely exceed a few percentages in commercial hatcheries and are unknown in the ocean. Numerous studies indicate that older biofilms are more attractive because they become thicker and more diverse (as reviewed by Salta et al. 2013) and comprise suspended particles and colloids along with important highly competitive biofilm-forming microorganisms that may mask or displace the "artificial biofilm." In that sense, experiments using Netlon collectors previously coated with selected microalgae and bacteria strains known to stimulate A. purpuratus settlement in the laboratory could not improve natural spat collection in the sea (Cantillanez et al. 2010). Thus, it is probable that the use of a specific microbial strain is not adequate in natural conditions where microbial communities are highly diverse and dynamic. As the majority of biofilm-forming bacteria are uncultivable, the use of advanced microbiological methods, such as "co-culture" (Marmann et al. 2014) or the use of highly inductive biofilms (as the one described in this study), as a microbial culture starter, should be evaluated along with the application of NGS as biofilm community monitoring tools.

\section{ACKNOWLEDGMENTS}

The authors thank the anonymous reviewers for their constructive comments on this manuscript. This research was partially supported by a grant from Innovate Perú (PITEI-2-P-200-071-14) and the CONCYTEC (assignment 132-2015-FONDECYT). JG was supported by a scholarship from IncaBiotec and the Tumbes Nacional University, and BD by the Franco Peruvian School of Life Sciences.

\section{REFERENCES}

Amann, R.I., Ludwig, W. \& Schleifer, K.H. 1995. Phylogenetic identification and in situ detection of individual microbial cells without cultivation. Microbiological Reviews, 59: 143-169.

Anderson, M.J. 1996. A chemical cue induces settlement of Sydney rock oysters, Saccostrea commercialis, in the laboratory and the field. Biological Bulletin, 190: 350-358. doi: 10.2307/1543027
Bankhead, P. 2014. Analyzing fluorescence microscopy images with imageJ. ImageJ, 1: 101-109.

Bao, W.Y., Yang, J.L., Satuito, C.G. \& Kitamura, H. 2007. Larval metamorphosis of the mussel Mytilus galloprovincialis in response to Alteromonas sp. 1: evidence for two chemical cues? Marine Biology, 152: 657-666. doi: 10.1007/s00227-007-0720-2

Bernendo-Quispe, D., León-Lluque, H., Montero-Gómez, E.E. \& Quispe-Cacho, J. 2016. Anuario estadístico pesquero y acuícola 2015. (No. 27). Ministerio de la Producción, Lima.

Brinkmeyer, R. 2016. Diversity of bacteria in ships ballast water as revealed by next-generation DNA sequencing. Marine Pollution Bulletin, 107: 277-285. doi: 10.1016/j.marpolbul.2016.03.058

Campbell, A.M., Fleisher, J., Sinigalliano, C., White, J.R. \& Lopez, J.V. 2015. Dynamics of marine bacterial community diversity of the coastal waters of the reefs, inlets, and wastewater outfalls of southeast Florida. Microbiology, 4: 390-408. doi: 10.1002/mbo3.245

Cantillanez, M., Riquelme, C. \& Avendano, M. 2010. Evaluacion en ambiente natural, del uso de biopeliculas marinas en el asentamiento larval de Argopecten purpuratus (Lamarck, 1819). Latin American Journal of Aquatic Research, 38: 47-56. doi: 10.3856/vol38issue1-fulltext-5

Courtois de Viçose, G., Viera, M., Bilbao, A. \& Izquierdo, M. 2010. Larval settlement of Haliotis tuberculatac coccinea in response to different inductive cues and the effect of larval density on settlement, early growth, and survival. Journal of Shellfish Research, 29: 587591. doi: $10.2983 / 035.029 .0306$

Dang, H., Li, T., Chen, M. \& Huang, G. 2008. Crossocean distribution of Rhodobacterales bacteria as primary surface colonizers in temperate coastal marine waters. Applied and Environmental Microbiology, 74: 52-60. doi: 10.1128/AEM.01400-07

Decelle, J., Romac, S., Stern, R.F., Bendif, E.M., Zingone, A. \& Audic, S., et al. 2015. PhytoREF: a reference database of the plastidial 16S rRNA gene of photosynthetic eukaryotes with curated taxonomy. Molecular Ecology Resources, 15: 1435-1445. doi: 10.1111/1755-0998.12401

Decho, A.W. 2000. Microbial biofilms in intertidal systems: an overview. Continental Shelf Research, 20: 1257-1273. doi: 10.1016/S0278-4343(00)00022-4

Dobretsov, S. \& Rittschof, D. 2020. Love at first taste: Induction of larval settlement by marine microbes. International Journal of Molecular Sciences, 21: 731. doi: 10.3390/ijms21030731

Eggleston, D.B., Lillis, A. \& Bohnenstiehl, D.R. 2016. Soundscapes and larval settlement: larval bivalve responses to habitat-associated underwater sounds. In: Popper, A.N. \& Hawkins, A. (Eds.). The effects of 
noise on aquatic life II. Springer, New York, pp. 255263. doi: 10.1007/978-1-4939-2981-8_30

Fitt, W.K., Coon, S.L., Walch, M., Weiner, R.M., Colwell, R.R. \& Bonar, D.B. 1990. Settlement behavior and metamorphosis of oyster larvae (Crassostrea gigas) in response to bacterial supernatants. Marine Biology, 106: 389-394. doi: 10.1007/BF01344317

Freckelton, M.L., Nedved, B.T. \& Hadfield, M.G. 2017. Induction of invertebrate larval settlement; different bacteria, different mechanisms? Scientific Reports, 7: 1-11. doi: 10.1038/srep42557

Fujimoto, M., Moyerbrailean, G.A., Noman, S., Gizicki, J.P., Ram, M.L., Green, P.A. \& Ram, J.L. 2014. Application of ion torrent sequencing to the assessment of the effect of alkali ballast water treatment on microbial community diversity. Plos One, 9: e107534. doi: 10.1371/journal.pone.0107534

Ganesan, A.M., Alfaro, A.C., Brooks, J.D. \& Higgins, C.M. 2010. The role of bacterial biofilms and exudates on the settlement of mussel (Perna canaliculus) larvae. Aquaculture, 306: 388-392. doi: 10.1016/j. aquaculture.2010.05.007

Godoy, F.A., Espinoza, M., Wittwer, G., Uriarte, I. \& Aranda, C. 2011. Characterization of culturable bacteria in larval cultures of the Chilean scallop Argopecten purpuratus. Ciencias Marinas, 37: 339348.

González-Hunt, R.M.G. 2010. Auge y crisis: la pesquería de la concha de abanico (Argopecten purpuratus) en la región Pisco-Paracas, costa sur del Perú. Espacio y Desarrollo, 20: 25-51.

Gosling, E. 2015. Marine bivalve molluscs. John Wiley and Sons, Hoboken.

Guerrero, P.M.B., León, J.P. \& Valdivia, L.M. 2016. Producción, comercialización y perspectivas de desarrollo de la acuicultura peruana. Científica, 11. doi: 10.21142/cient.v11i2.191

Hadfield, M.G. 2011. Biofilms and marine invertebrate larvae: what bacteria produce that larvae use to choose settlement sites. Annual Review of Marine Science, 3: 453-470. doi: 10.1146/annurev-marine-120709142753

Harvey, M., Bourget, E. \& Ingram, R.G. 1995. Experimental evidence of passive accumulation of marine bivalve larvae on filamentous epibenthic structures. Limnology and Oceanography, 40: 94-104.

Helm, M.M. \& Bourne, N. 2004. Hatchery culture of bivalves (a practical manual). FAO Fisheries Technical Paper. No. 471: 177 pp.

Huggett, M.J., Williamson, J.E., De Nys, R., Kjelleberg, S. \& Steinberg, P.D. 2006. Larval settlement of the common Australian sea urchin Heliocidaris erythrogramma in response to bacteria from the surface of coralline algae. Oecologia, 149: 604-619. doi: 10.1007/s00442-006-0470-8
Jiang, J.-Z., Zhao, W., Liu, G.-F. \& Wang, J.-Y. 2017. Relationships between and formation dynamics of the microbiota of consumers, producers, and the environment in an abalone aquatic system. Plos One, 12: e0182590. doi: 10.1371/journal.pone.0182590

Keawtawee, T., Fukami, K. \& Songsangjinda, P. 2012. Use of a noctiluca-killing bacterium Marinobacter salsuginis strain BS2 to reduce shrimp mortality caused by Noctiluca scintillans. Fisheries Science, 78: 641-646. doi: 10.1007/s12562-012-0497-1

Kermarrec, L., Franc, A., Rimet, F., Chaumeil, P., Humbert, J.F. \& Bouchez, A. 2013. Next-generation sequencing to inventory taxonomic diversity in eukaryotic communities: a test for freshwater diatoms. Molecular Ecology Resources, 13: 607-619. doi: 10.1111/1755-0998.12105

Khandeparker, L., Anil, A.C. \& Raghukumar, S. 2002. Factors regulating the production of different inducers in Pseudomonas aeruginosa with reference to larval metamorphosis in Balanus amphitrite. Aquatic Microbial Ecology, 28: 37-54. doi: 10.3354/ame02 8037

Lau, S.C., Mak, K.K., Chen, F. \& Qian, P.Y. 2002. Bioactivity of bacterial strains isolated from marine biofilms in Hong Kong waters for the induction of larval settlement in the marine polychaete Hydroides elegans. Marine Ecology Progress Series, 226: 301310.

Lee, J., Lee, J., Lee, M., Lee, K.J.B. \& Ko, D.S. 2004. Scanning confocal fluorescence microscopy of single DNA-EtBr complexes dispersed in polymer. Chemical Physics Letters, 394: 49-53. doi: 10.1016/j.cplett. 2004.06.105

Leyton, Y.E. \& Riquelme, C.E. 2008. Use of specific bacterial-microalgal biofilms for improving the larval settlement of Argopecten purpuratus (Lamarck, 1819) on three types of artificial spat-collecting materials. Aquaculture, 276: 78-82. doi: 10.1016/j.aquaculture. 2008.01.037

Marmann, A., Aly, A.H., Lin, W., Wang, B. \& Proksch, P. 2014. Co-cultivation-a powerful emerging tool for enhancing the chemical diversity of microorganisms. Marine Drugs, 12: 1043-1065. doi: 10.3390/md 12021043

Marsden, J.E. \& Lansky, D.M. 2000. Substrate selection by settling zebra mussels, Dreissena polymorpha, relative to material, texture, orientation, and sunlight. Canadian Journal of Zoology, 78: 787-793. doi: 10.1139/z00-004

Mitra, S., Gachhui, R. \& \& Mukherjee, J. 2015. Enhanced biofilm formation and melanin synthesis by the oyster settlement-promoting Shewanella colwelliana is related to hydrophobic surface and simulated intertidal 
environment. Biofouling, 31: 283-296. doi: 10.1080/ 08927014.2015.1038705

Mueller, L.N., De Brouwer, J.F.C., Almeida, J.S., Stal, L.J. \& Xavier, J.B. 2006. Analysis of a marine phototrophic biofilm by confocal laser scanning microscopy using the new image quantification software PHLIP. BMC Ecology, 6: 1-15. doi: 10.1186/1472-6785-6-1

Murias, A. 2015. Cae exportación de conchas de abanico. Fish Information and Services, Tokyo. [https://fis. com/fis/worldnews/worldnews.asp?l=s\&id=74278\&n $\mathrm{db}=1$ ]. Reviewed: May 19, 2017.

Natrah, F.M.I., Bossier, P., Sorgeloos, P., Yusoff, F.M. \& Defoirdt, T. 2014. Significance of microalgal-bacterial interactions for aquaculture. Reviews in Aquaculture, 6: 48-61. doi: $10.1111 /$ raq. 12024

Pacheco, A. \& Stotz, W.B. 2006. Will providing a filamentous substratum in the water column and shell litter on the bottom increase settlement and post-larval survival of the scallop Argopecten purpuratus? Journal of Experimental Marine Biology and Ecology, 333: 27-39. doi: 10.1016/j.jembe.2005.11.017

Palacios, L., Arahal, D.R., Reguera, B. \& Marín, I. 2006. Hoeflea alexandrii sp. nov., isolated from the toxic dinoflagellate Alexandrium minutum AL1V. International Journal of Systematic and Evolutionary Microbiology, 56: 1991-1995. doi: 10.1099/ijs.0.64 238-0

Palomino-Ramos, A.R. 2004. Manual de cultivo suspendido de concha de abanico. FONDEPES, Lima.

Parsons, G.J., Dadswell, M.J. \& Roff, J.C. 1993. Influence of biofilm on settlement of sea scallop, Placopecten magellanicus (Gmelin, 1791), in Passamaquoddy Bay, New Brunswick, Canada. Journal of Shellfish Research, 12: 279-283.

Patel, P., Callow, M.E., Joint, I. \& Callow, J.A. 2003. Specificity in the settlement - modifying response of bacterial biofilms towards zoospores of the marine alga Enteromorpha. Environmental Microbiology, 5: 338-349.

Peng, L.H., Liang, X., Xu, J.K., Dobretsov, S. \& Yang, J.L. 2020. Monospecific biofilms of Pseudoalteromonas promote larval settlement and metamorphosis of Mytilus coruscus. Scientific Report, 10: 2557. doi: 10.1038/ s41598-020-59506-1

Railkin, A.I. 2003. Marine biofouling: colonization processes and defenses. CRC Press, Boca Raton.

Ramanan, R., Kim, B.H., Cho, D.H., Oh, H.M. \& Kim, H.S. 2016. Algae-bacteria interactions: evolution, ecology and emerging applications. Biotechnology Advances, 34: 14-29. doi: 10.1016/j.biotechadv.2015. 12.003
Ritchie, K.B. 2012. Bacterial symbionts of corals and symbiodinium, In: Rosenberg, E. \& Gophna, U. (Eds.). Beneficial microorganisms in multicellular life forms. Springer, Berlin, pp. 139-150. doi: 10.1007 1978-3-642-21680-0_9

Salta, M., Wharton, J.A., Blache, Y., Stokes, K.R. \& Briand, J.-F. 2013. Marine biofilms on artificial surfaces: structure and dynamics. Environmental Microbiology, 15: 2879-2893. doi: 10.1111/14622920.12186

Satuito, C.G., Bao, W., Yang, J. \& Kitamura, H. 2005. Survival, growth, settlement and metamorphosis of refrigerated larvae of the mussel Mytilus galloprovincialis Lamarck and their use in settlement and antifouling bioassays. Biofouling, 21: 217-225. doi: 10.1080/08927010500375300

Saucedo, P.E., Bervera-León, H., Monteforte, M., Southgate, P.C. \& Monsalvo-Spencer, P. 2005. Factors influencing recruitment of hatchery-reared pearl oyster (Pinctada mazatlanica; Hanley 1856) spat. Journal of Shellfish Research, 24: 215-219. doi: 10.2983/0730-8000(2005)24[215: FIROHR]2.0.CO;2

Schink, B. 2006. The genus Pelobacter. The prokaryotes. Springer, Berlin, pp. 5-11.

Sharp, K.H., Sneed, J.M., Ritchie, K.B., Mcdaniel, L. \& Paul, V.J. 2015. Induction of larval settlement in the reef coral Porites astreoides by a cultivated marine Roseobacter Strain. Biological Bulletin, 228: 98-107. doi: 10.1086/BBLv228n2p98

Shikuma, N.J. \& Hadfield, M.G. 2005. Temporal variation of an initial marine biofilm community and its effects on larval settlement and metamorphosis of the tubeworm Hydroides elegans. Biofilms, 2: 231-238. doi: $10.1017 /$ S1479050506002018

Steven, B., McCann, S. \& Ward, N.L. 2012. Pyrosequencing of plastid 23S rRNA genes reveals diverse and dynamic cyanobacterial and algal populations in two eutrophic lakes. FEMS Microbial Ecology, 82: 607-615. doi: 10.1111/j.1574-6941.2012.01429.x

Su, Z., Huang, L., Yan, Y. \& Li, H. 2007. Effect of different substrates on pearl oyster Pinctada martensii (Dunker) larvae settlement. Aquaculture, 271: 377383.

Tamburri, M.N., Zimmer-Faust, R.K. \& Tamplin, M.L. 1992. Natural sources and properties of chemical inducers mediating settlement of oyster larvae: a reexamination. Biological Bulletin, 183: 327-338. doi: $10.2307 / 1542218$

Tarazona, J. \& Arntz, W. 2001. The Peruvian coastal upwelling system. In: Seeliger, U. \& Kjerfve, B. (Eds.). Coastal marine ecosystems of Latin America, ecological studies. Springer, Berlin, pp. 229-244. doi: 10.1007/978-3-662-04482-7_17 
Taylor, J.J., Southgate, P.C. \& Rose, R.A. 1998. Assessment of artificial substrates for collection of hatchery-reared silver-lip pearl oyster (Pinctada maxima, Jameson) spat. Aquaculture, 162: 219-230. doi: 10.1016/S0044-8486(98)00213-0

Toupoint, N., Mohit, V., Linossier, I., Bourguignon, N., Myrand, B., Olivier, F., Lovejoy, C. \& Tremblay, R. 2012. Effect of biofilm age on settlement of Mytilus edulis. Biofouling, 28: 985-1001. doi: 10.1080/08927 014.2012.725202

Van Colen, C., Lenoir, J., De Backer, A., Vanelslander, B., Vincx, M., Degraer, S. \& Ysebaert, T. 2009. Settlement of Macoma balthica larvae in response to benthic diatom films. Marine Biology, 156: 21612171. doi: 10.1007/s00227-009-1246-6

Vijayan, N. \& Hadfield, M. 2020. Bacteria known to induce settlement of larvae of Hydroides elegans are rare in natural inductive biofilm. Aquatic Microbial Ecology, 84: 31-42. doi: 10.3354/ame01925

Wang, C., Bao, W.Y., Gu, Z.Q., Li, Y.F., Liang, X., Ling, Y., et al. 2012. Larval settlement and metamorphosis of the mussel Mytilus coruscus in response to natural biofilms. Biofouling, 28: 249-256. doi: 10.1080/08927 014.2012.671303

Wassnig, M. \& Southgate, P.C. 2012. Effects of settlement cues on behaviour and substrate attachment of hatchery reared winged pearl oyster (Pteria penguin) larvae. Aquaculture, 344-349: 216-222. doi: 10.1016/j.aquaculture.2012.03.020

William, S. \& Feil, H. 2012. Bacterial genomic DNA isolation using CTAB. Sigma, 50: 6876.

Received: 30 April 2020; Accepted: 16 September 2020
Yang, J.-L., Shen, P.-J., Liang, X., Li, Y.-F., Bao, W.-Y. \& Li, J.-L. 2013. Larval settlement and metamorphosis of the mussel Mytilus coruscus in response to monospecific bacterial biofilms. Biofouling, 29: 247259. doi: 10.1080/08927014.2013.764412

Yoon, S.H., Ha, S.M., Kwon, S., Lim, J., Kim, Y., Seo, H. \& Chun, J. 2017. Introducing EzBioCloud: a taxonomically united database of $16 \mathrm{~S}$ rRNA and whole genome assemblies. International Journal of Systematic and Evolutionary Microbiology, 67: 16131617.

Yu, X., He, W., Gu, J.-D., He, M. \& Yan, Y. 2008. The effect of chemical cues on settlement of pearl oyster Pinctada fucata martensii (Dunker) larvae. Aquaculture, 277: 83-91. doi: 10.1016/j.aquaculture.2008. 02.010

Zhao, B., Zhang, S. \& Qian, P.-Y. 2003. Larval settlement of the silver- or goldlip pearl oyster Pinctada maxima (Jameson) in response to natural biofilms and chemical cues. Aquaculture, 220: 883-901. doi: 10.1016/S00448486(02)00567-7

Zimmermann, J., Glöckner, G., Jahn, R., Enke, N. \& Gemeinholzer, B. 2015. Metabarcoding vs. morphological identification to assess diatom diversity in environmental studies. Molecular Ecology Resources, 15: 526-542. doi: 10.1111/1755-0998.12336 